half of 2013 and the Council will present its recommendation for Editor-elect to the membership for their consideration at the 2014 Executive session. All Active and Senior Members are strongly encouraged to consider pursuing this important position. Interested applicants should contact Ryan Walther at the editorial offices of the Journal at (978) 927-8330 or rwalther@aats.org for position description and application information.

\section{AATS/ACCF Heart Valve Summit 2013: Medical, Surgical, and Interventional Decision Making}

September 26-28, 2013

Chicago Marriott Downtown Magnificent Mile

Chicago, IL, USA

Sessions Include:

Basics of Aortic Stenosis

New Treatment Approaches

Tough Issues in AS Management

The Intermediate (and Low-Risk) Patient

Mitral Regurgitation: Anatomy, Imaging, Decision Making

Mitral Valve Regurgitation in Heart Failure

Complications Associated With Mitral Valve Disease:

Real Cases

HOCM and Mitral Regurgitation

Tricuspid Valve Disease

Failed Mitral Valve Surgery

Valvular Heart Disease: The Future

Management Challenges in Valve Disease

Honored Lecturers:

Tirone E. David, MD, FRCS, "Reconstructive Valve

Surgery-A Career of Learning"
Rick Nishimura, MD, FACC, "Challenges in Guidelines Development for Valvular Heart Disease"

View the Full Program, Register, and Reserve Housing at www.aats.org/valve

\section{AATS Focus on Thoracic Surgery: Esophageal Disease}

November 15-16, 2013

Boston Marriott Copley Place

Boston, MA, USA

\section{AATS Awards Applications}

Now Available at www.aats.org

AATS Critical Care Scholarship provides an opportunity for cardiothoracic surgery residents to attend the 2013 CVT Critical Care conference on October 10-12, 2013, in Washington, DC

- Residents must be attending an ACGME accredited cardiothoracic surgical training program in the United States or RCPSC accredited cardiothoracic surgical residency program in Canada.

- The AATS will provide a stipend of $\$ 500$ to the resident's institution to help offset the cost of travel and hotel accommodations.

- Recipients will received complimentary registration to the Critical Care Conference.

- Participation is limited to one resident per institution and up to 75 recipients will be selected for this award on a first come first served basis.

Deadline: August 30, 2013

\section{The Western Thoracic Surgical Association}

\section{Applications for Membership}

The WTSA is now accepting Applications for Membership online for Active as well as Candidate membership status. Visit the WTSA Web site at Www.westernthoracic.org to read the complete membership eligibility requirements and to initiate an online application.

\section{Active Member}

$\$ 325.00$ annually, plus $\$ 50.00$ initiation fee
Applicant must meet all membership criteria, including but not limited to:

- Reside within or have completed a cardiothoracic residency training program within the geographic limits of the Association.

- Have been engaged in the practice of thoracic and cardiovascular surgery for at least three years following completion of postgraduate training. If a candidate completed his/her thoracic surgical residency in an institution within the geographic limits of the Association, such completion may count toward one of the three years of practice.

- Have a full and unrestricted license to practice medicine in his or her respective state or province, and 
have a current appointment on the surgical staff of a hospital with no reportable action pending which could adversely affect such applicant's staff privileges at any hospital.

\section{Candidate Member}

$\$ 100.00$ annually

Applicant must meet all membership criteria, including but not limited to:

- Be matched or enrolled in either a cardiothoracic surgery education program accredited by the Residency Review Committee for Thoracic Surgery under the authority of the ACGME or a program approved for cardiothoracic surgery education by the Royal College of Surgeons of Canada-or their equivalency-from within the Association's geographic limits. Individuals who have completed their education in one of the above programs and are in the process of acquiring certification in cardiothoracic surgery by either the American Board of Tho- racic Surgery or the Royal College of Surgeons of Canada also are eligible to apply for Candidate membership.

An application must include the following uploads: a photo; a complete curriculum vitae with bibliography; and, for Active applicants, the 3 most significant articles that $\mathrm{s} /$ he personally wrote. The application must be completed and submitted online by March 1, 2013, and all support letter(s) (three for Active applicants, one for Candidates) uploaded by that applicant's sponsor(s) by March 31, 2013, in order for the applicant to be considered for election to membership at the 2013 Annual Meeting.

\section{WTSA 40th Annual Meeting}

\section{Save the Date!}

June 25-28, 2014

The St. Regis Monarch Beach

Dana Point, California

\section{The American Board of Thoracic Surgery}

\section{Notices}

The part I (written) examination was held on December 3. It is planned that this examination will be given at multiple sites throughout the United States using an electronic format. The closing date for registration is August 1 each year. Those wishing to be considered for examination must apply online at www.abts.org.

To be admissible for the Part II (oral) examination, a candidate must have successfully completed the Part I (written) examination.

A candidate applying for admission to the certifying examination must fulfill all the requirements of the Board in force at the time the application is received. Please address all communications to the American Board of Thoracic Surgery, 633 North St Clair Street, Suite 2320, Chicago, IL 60611 (telephone: 312-202-5900).

\section{Requirements for Maintenance of Certification}

Diplomates of the American Board of Thoracic Surgery (ABTS) who plan to participate in the Maintenance of Certification (MOC) process must hold an unrestricted medical license in the locale of their practice and privileges in a hospital accredited by the JCAHO (or other organization recognized by the ABTS). In addition, a valid ABTS certificate is an absolute requirement for entrance into the Maintenance of Certification process. If your certificate has expired, the only pathway for renewal of a certificate is to take and pass the Part I (written) and the Part II (oral) certi- fying examinations. The names of individuals who have not maintained their certificate will no longer be published in the American Board of Medical Specialties Directories. Diplomates' names will be published upon successful completion of the Maintenance of Certification process.

The CME requirements are 30 Category I credits earned during each year prior to application. At least half of these CME hours need to be in the broad area of thoracic surgery. Category II credits are not allowed. Interested individuals should refer to the Booklet of Information for Maintenance of Certification for a complete description of acceptable CME credits. Diplomates will be expected to submit verification of CME earned.

Diplomates in the Maintenance of Certification process will need to provide a summary of their major cases performed during the year prior to application. The practice review should not exceed 100 cases.

Diplomates in the Maintenance of Certification process will be required to complete all sections of the SESATS self-assessment examination. It is not necessary for Diplomates to purchase SESATS individually, because it will be sent to them after their application has been approved.

Diplomates may apply for Maintenance of Certification in the year their certificate expires, or if they wish to do so, they may apply up to two years before it expires. However, the new certificate will be dated 10 years from the date of expiration of their original certificate or most recent recertification certificate. In other words, going through the Maintenance of Certification process early does not alter the 10-year validation. Diplomates certified prior to 1976 (the year that time-limited certificates were initiated) are also required to participate in MOC if they wish to maintain valid certificates. 